\title{
Progesterone Receptor Together with PKC $\alpha$ Expression as Prognostic Factors for Astrocytomas Malignancy
}

Denisse Arcos-Montoya (iD)

Talia Wegman-Ostrosky ${ }^{2,3}$

Sonia Mejía-Pérez (D) ${ }^{4}$

Marisol De la Fuente-Granada' Ignacio Camacho-Arroyo ${ }^{5}$ Alejandro García-Carrancá (iD) Marco A Velasco-Velázquez (iD) Joaquín Manjarrez-Marmolejo Aliesha González-Arenas (iD)

'Departamento de Medicina Genómica y Toxicología Ambiental, Instituto de Investigaciones Biomédicas, Universidad Nacional Autónoma de México, Ciudad de México, México; ${ }^{2}$ Dirección de Investigación, Instituto Nacional Cancerología, Ciudad de México, México; ${ }^{3}$ División de Investigación Básica, Instituto Nacional de Cancerología, Ciudad de México, México; ${ }^{4}$ Subdirección de Neurocirugía, Instituto Nacional de Neurología y Neurocirugía, Ciudad de México, México; ${ }^{5}$ Unidad de Investigación en Reproducción Humana, Instituto Nacional de

Perinatología-Facultad de Química, Universidad Nacional Autónoma de México, Ciudad de México, México; ${ }^{6}$ Unidad de Investigación Biomédica en Cáncer, Instituto de Investigaciones Biomédicas, Universidad Nacional Autónoma de México e Instituto Nacional de Cancerología, Ciudad de México, México; ${ }^{7}$ Departamento de Farmacología, Facultad de Medicina, Universidad Naciona Autónoma de México, Ciudad de México, México; ${ }^{8}$ Laboratorio de Fisiología de la Formación Reticular, Instituto Nacional de Neurología y Neurocirugía, Ciudad de México. México
Correspondence: Aliesha González-Arenas Departamento de Medicina Genómica y Toxicología Ambiental, Instituto de Investigaciones Biomédicas, Universidad Nacional Autónoma de México, Ciudad Universitaria, Ciudad de México, 04510, México

Tel +525556229209

Email alieshag@iibiomedicas.unam.mx
Introduction: Astrocytomas are the most common and aggressive primary brain tumors, and they are classified according to the degree of malignancy on a scale of I to IV, in which grade $\mathrm{I}$ is the least malignant and grade IV the highest. Many factors are related to astrocytomas progression as progesterone receptor (PR), whose transcriptional activity could be regulated by phosphorylation by protein kinase $\mathrm{C}$ alpha $(\mathrm{PKC} \alpha)$ at the residue Ser400. Our aim was to investigate if PR phosphorylation together with $\mathrm{PKC} \alpha$ expression could be used as a prognostic factor for astrocytomas malignancy.

Methods: By immunofluorescence, we detected the content of PKC $\alpha, \mathrm{PR}$ and its phosphorylation at Ser400 in 46 biopsies from Mexican patients with different astrocytoma malignancy grades; by bioinformatic tools using TCGA data, we evaluated the expression of PR and PKC $\alpha$ mRNA according to astrocytoma malignancy grades. For all statistical analyses, significance was $\mathrm{p}<0.05$.

Results: We detected a positive correlation between the tumor grade and the content of PKC $\alpha$, PR and its phosphorylation at Ser400, as well as the intracellular colocalization of these proteins. Interestingly, using an in silico assay, we found that the PR and PKC $\alpha$ expression at mRNA level has an inverse ratio with astrocytomas tumor grade.

Discussion: These results indicate that PR and its phosphorylation at Ser400 site, as well as PKC $\alpha$ and their colocalization, could be considered as possible malignancy biomarkers for astrocytomas grades I-IV.

Keywords: astrocytoma, glioblastoma, progesterone receptor, protein kinase C alpha, biomarker

\section{Introduction}

Astrocytomas are the most common primary brain tumors which represent about $76 \%$ of all gliomas ${ }^{1}$ and can be found in any part of the brain, especially in the brain cortex, thalamus and basal ganglia. ${ }^{2}$ The World Health Organization (WHO) proposed a scale from I to IV for their classification, according to the degree of malignancy. Grade I exhibits the lower degree and grade IV or glioblastoma (GBM) exhibits more advanced features of malignancy, including vascular proliferation, mitosis and necrosis, typically associated with rapid disease evolution and with poor prognosis. ${ }^{3}$ Epidemiological data report that GBM occurs in a greater proportion in men than in women $(3: 2) .^{2}$ The average survival of patients with astrocytoma depends on the histological grade, 7 years for patients with astrocytoma grade II, 3 years for grade III, and 12-15 months for patients with glioblastoma, 
Table I Clinic and Pathological Characteristics from 46 Astrocytic Tumor Samples

\begin{tabular}{|c|c|c|c|}
\hline MR & Age & HAG & Sex \\
\hline 101 & 17 & I-II & $M$ \\
\hline 102 & 18 & I-II & $\mathrm{F}$ \\
\hline 103 & 26 & I-II & $\mathrm{F}$ \\
\hline 104 & 22 & I & $\mathrm{F}$ \\
\hline 105 & 40 & I & $F$ \\
\hline 206 & 25 & II & $M$ \\
\hline 207 & 34 & II & $\mathrm{F}$ \\
\hline 208 & 56 & II & $M$ \\
\hline 209 & 35 & II & $M$ \\
\hline 310 & 30 & III & $M$ \\
\hline 311 & 73 & III & $M$ \\
\hline 312 & 68 & III & $M$ \\
\hline 313 & 66 & III & $M$ \\
\hline 314 & 48 & III & $\mathrm{F}$ \\
\hline 315 & 55 & III & $M$ \\
\hline 316 & 38 & III & $\mathrm{F}$ \\
\hline 317 & 65 & III & $F$ \\
\hline 318 & 48 & III & $\mathrm{F}$ \\
\hline 319 & 66 & III & $M$ \\
\hline 320 & 27 & III & $F$ \\
\hline 321 & 32 & III & $F$ \\
\hline 422 & 16 & IV & $F$ \\
\hline 423 & 23 & IV & $M$ \\
\hline 424 & 50 & IV & $M$ \\
\hline 425 & 55 & IV & $F$ \\
\hline 426 & 27 & IV & $M$ \\
\hline 427 & 48 & IV & $M$ \\
\hline 428 & 43 & IV & $\mathrm{F}$ \\
\hline 429 & 74 & IV & $F$ \\
\hline 430 & 27 & IV & $M$ \\
\hline 431 & 39 & IV & $M$ \\
\hline 432 & 66 & IV & $M$ \\
\hline 433 & 16 & IV & $M$ \\
\hline 444 & 41 & IV & $M$ \\
\hline 445 & 52 & IV & $F$ \\
\hline 446 & 29 & IV & $M$ \\
\hline 447 & 44 & IV & $M$ \\
\hline 448 & 70 & IV & $F$ \\
\hline 449 & 48 & IV & $F$ \\
\hline 450 & 56 & IV & $M$ \\
\hline 451 & 61 & IV & $F$ \\
\hline 452 & 46 & IV & $F$ \\
\hline 453 & 79 & IV & $M$ \\
\hline 454 & 56 & IV & $M$ \\
\hline 455 & 21 & IV & $F$ \\
\hline 456 & 49 & IV & $F$ \\
\hline 057 & 34 & NT & $\mathrm{F}$ \\
\hline 058 & 18 & NT & $F$ \\
\hline 059 & 26 & NT & $\mathrm{F}$ \\
\hline 060 & 20 & NT & $F$ \\
\hline
\end{tabular}

(Continued)
Table I (Continued).

\begin{tabular}{|l|c|c|c|}
\hline MR & Age & HAG & Sex \\
\hline 061 & 49 & NT & F \\
062 & 18 & NT & F \\
\hline
\end{tabular}

Note: (-) information was not available

Abbreviations: MR, medical reference; HAG, histological astrocytoma grade; NT, non-Tumor.

even with the standard treatment (radiotherapy + temozolomide). ${ }^{4}$ The National Institute of Neurology and Neurosurgery (INNN) reports that in Mexico, 9\% of all brain tumors are GBM, ${ }^{5}$ which present an incidence of 3.5 per 100,000 habitants $^{6}$ and, particularly for the Mexican population, the average of diagnosis is 49 years old. ${ }^{6}$

Some factors support the development of astrocytomas, for example, the activated pathways of NFkB, PI3K/AKT and the expression of progesterone receptor $(\mathrm{PR}){ }^{7,8}$ Regarding PR, immunohistochemical analysis revealed higher detection of this receptor in GBM compared with lower-grade malignant tumors; ${ }^{9}$ furthermore, blocking this receptor with RU486 antagonist reduces proliferation, migration, and invasion of GBM derived cell lines. ${ }^{10}$ In in vivo models, the size of tumors resulting from heterotopic and orthotopic xenograft of murine glioma cells (a tumor-like glioblastoma) decreased by $50 \%$ after treatment with RU486. ${ }^{11-13}$

PR receptor belongs to the family of the nuclear transcriptional regulators that can be activated by ligand or without it ${ }^{14,15}$; PR presents post-translational modifications, such as phosphorylation, sumoylation, acetylation and ubiquitylation. ${ }^{16}$ The state of phosphorylation of the PR affects its transcriptional activity, cellular localization, specificity and replacement rate. ${ }^{17}$ At the moment, for the human PR, 15 phosphorylation sites have been recognized. ${ }^{18-21}$ The residue Ser400 can be basally phosphorylated and in response to mitogens, and this phosphorylation is necessary for the regulation of ligand-independent activity. ${ }^{22}$ Our group has identified that the protein kinase $\mathrm{C}$ ( $\mathrm{PKC}$ ) is able to phosphorylate $\mathrm{PR}$ in this residue, in two cell lines derived from GBM. $^{23,24}$

The protein kinases $\mathrm{C}(\mathrm{PKC})$ are a family of isoenzymes that have the activity of Ser/Thr kinases. These proteins participate in many signaling pathways and are implicated in diverse cellular responses. ${ }^{25}$ The overexpression or hyper-activation of $\mathrm{PKC}$ is a characteristic 
Table 2 Clinical Pathological Features of the Samples from Data Bases TCGA and GTEX

\begin{tabular}{|l|c|c|c|c|}
\hline $\begin{array}{l}\text { Clinical Pathological } \\
\text { Features }\end{array}$ & $\begin{array}{c}\text { Non- } \\
\text { Tumor }\end{array}$ & G II & GIII & GIV \\
\hline $\mathrm{n}$ & 283 & 258 & $27 \mathrm{I}$ & 166 \\
\hline Mean age & - & 39.9 & 45.5 & 59.4 \\
\hline Survival (months) & - & 37.6 & 28.3 & 14.2 \\
\hline
\end{tabular}

Note: (-) information was not available.

Abbreviation: $\mathrm{G}$, astrocytoma grade.

of $\mathrm{GBM}^{26}$; some studies show that the activity of PKC is increased in cell lines derived from gliomas, and the PKC inhibitors reduce their proliferation significantly. ${ }^{27}$ Isotypes PKC $\alpha$ and PKC $\delta$ are expressed in U373 cells (cell line derived from astrocytoma grade III) and its activation induces proliferation, migration and invasiveness, ${ }^{23}$ interestingly through an interaction between PKC $\alpha$ and PR, which does not exist with the isotype $\delta .^{28}$
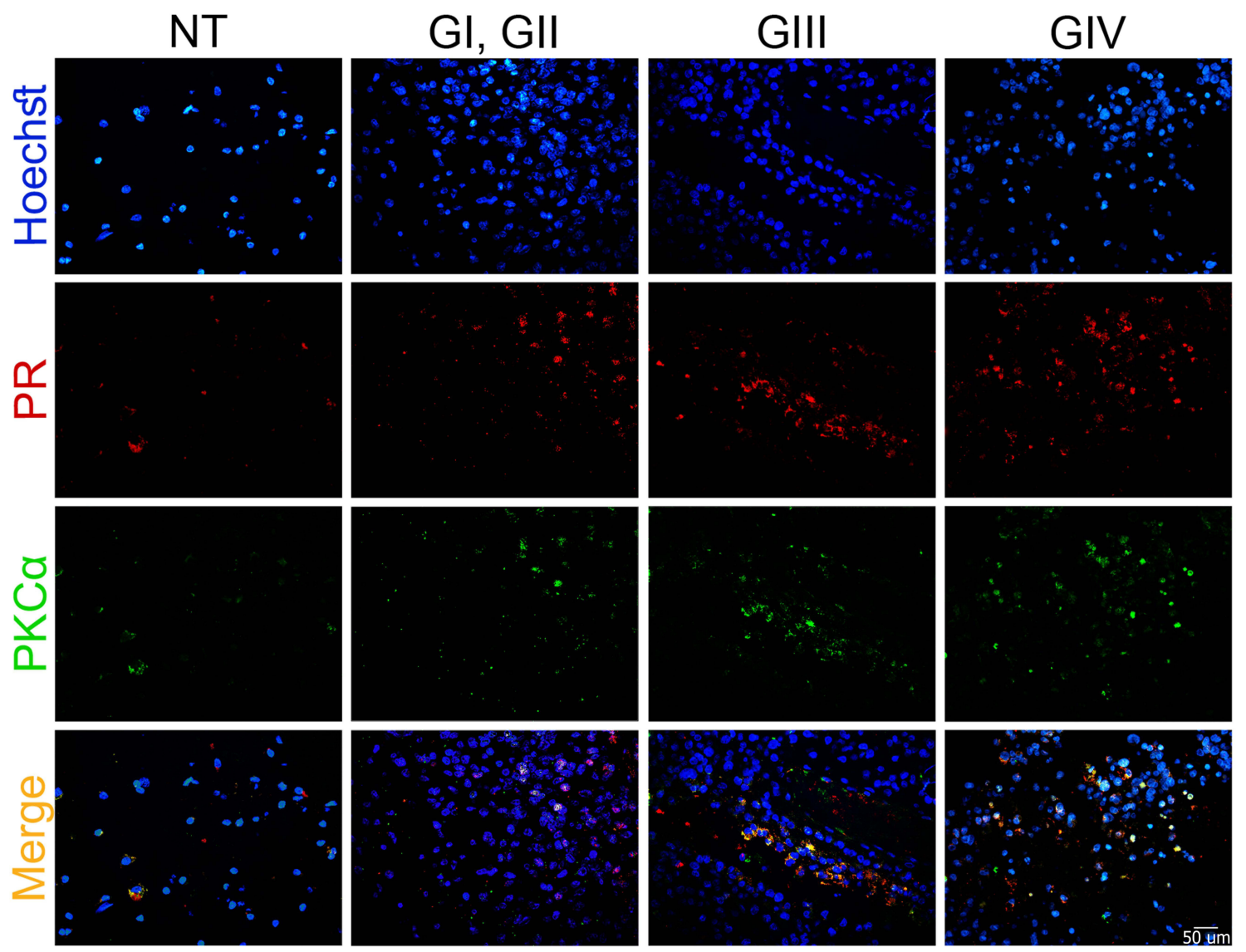

Figure I PR, PKC $\alpha$ localization, and their merge increase according to the astrocytoma grade. Representative sections of astrocytic tumors from (NT) non-tumor tissue, (G) astrocytomas grade, which were immunostained vs PR and PKC $\alpha$. Blue: nucleus, green: PKC $\alpha$, red: PR and orange: merge among the three channels (original magnification, 600x). 
were classified according to the WHO histopathological classification (low grade: 9 samples, grade III: 12 samples, and 25 samples for GBM) (Table 1). For this work, six pathology slides of brain epileptic foci (women) were obtained, which were used as non-tumoral tissue.

\section{Immunofluorescence}

The slides were dewaxed in a dry bath at $60^{\circ} \mathrm{C}$ for 50 minutes; after that, they were passed for the following gradients: xylol, xylol:ethanol (1:1), ethanol (100\%), ethanol $(96 \%)$ and ethanol $(90 \%)$, for 5 minutes each. For the identification of antigens, the epitopes were exposed to a solution of sodium citrate $(10 \mathrm{mM}, \mathrm{pH} 6.0)$, boiling for an hour. The tissue was blocked in $5 \%$ normal goat serum/ TBS-Tween $0.01 \%$ (blocking buffer) overnight at $4{ }^{\circ} \mathrm{C}$; the sections were washed and then incubated with the primary antibodies: rabbit anti-PR $(2 \mu \mathrm{g} / \mathrm{mL})$ (sc-7208, Santa Cruz Biotechnology, Dallas, TX) and mouse anti-PKC $\alpha(2 \mu \mathrm{g} /$ mL) (sc-8393, Santa Cruz Biotechnology, Dallas, TX) and rabbit anti-PR pSer400 $(1.3 \mu \mathrm{g} / \mathrm{mL})\left(\mathrm{ab} 60954\right.$, Abcam) at $4^{\circ}$ $\mathrm{C}$ overnight. The antibodies were removed and the sections were washed three times with TBS-Tween $0.1 \%$ for 5 minutes and then incubated with secondary antibodies at room temperature for 1 hour: Alexa Fluor 488 anti-mouse (1:1000) (A11001, Life Technologies, Carlsbad, CA) and Alexa Fluor 594 anti-rabbit (2 drops $/ \mathrm{mL}$ according with the guide) (R37117, Molecular Probes by Life Technologies, Carlsbad, CA). Nuclei were stained with Hoechst 3342 (Thermo Scientific, Waltham, MA). Sections were covered from light, washed, mounted with Fluoro Care Anti-Fade Mountant (Biocare Medical, Concord, CA) and visualized in an Olympus Bx43 fluorescence microscope. The images were analyzed using the program Image-Pro Plus 7.0 Media Cybernetics (Rockville, MD). Twenty-five fields were taken for each sample; subsequently, the fluorescence intensity for each field was evaluated, considered as a proportional measure of the density of positive cells. Finally, the values were averaged to have a unique value for each patient. An immunofluorescence control was done using samples and secondary antibody, non-signal was detected. Two persons determined fluorescence intensity for each sample independently and blinded (no one knew the malignancy grade of samples).

\section{Results Classification}

In order to define three intervals for the fluorescence intensity as low, medium, or high for PR or PKC $\alpha$ based on the average of 25 fields per sample, we used the formula
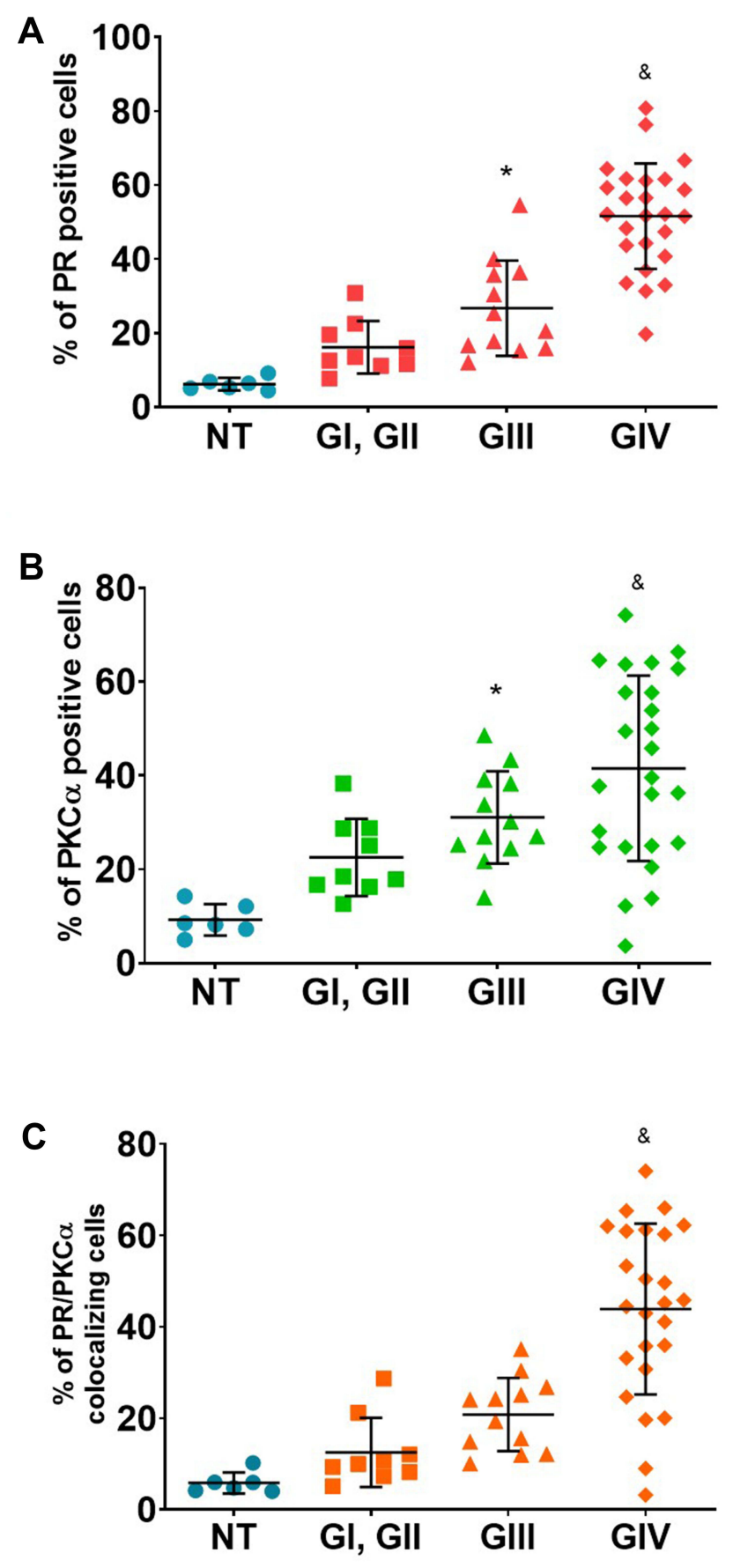

Figure 2 Percentage of positive cells for PR, PKC $\alpha$ and their merge. Percentage of positive cells for PR (A) for PKC $\alpha$ (B) and their colocalization PR/PKC $\alpha$ (C). For each sample, 25 fields were taken. Results are expressed as the mean \pm SD. Dunnet post-test determined the statistical difference (*p $\leq 0.05$ vs NT and ${ }^{*} p \leq 0.05$ vs all groups).

Abbreviations: NT, non-tumor; G, astrocytomas grade.

modified from Villegas-Pineda et al. ${ }^{29} \mathrm{I}=(\mathrm{H}-\mathrm{L}) / 3$, where $\mathrm{I}$ is the intensity, $\mathrm{H}$ is the highest intensity value of all samples and $\mathrm{L}$ is the lowest intensity value of non-tumoral tissue. With this formula, we can define the intervals as follows: 


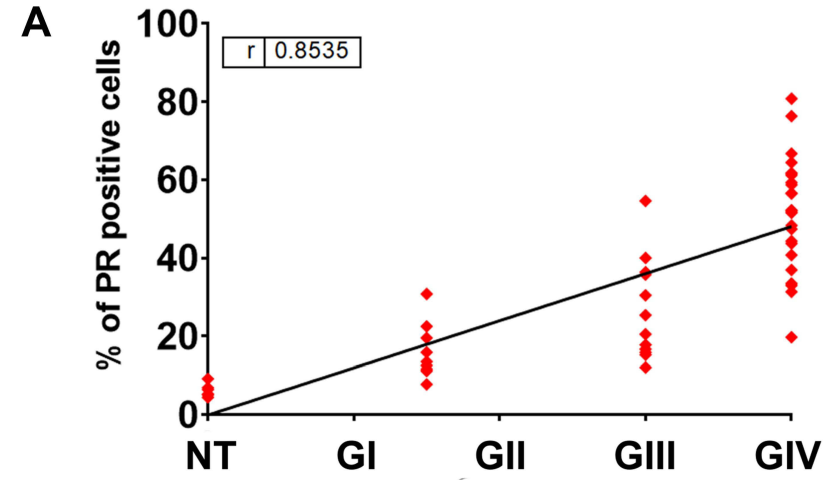

B
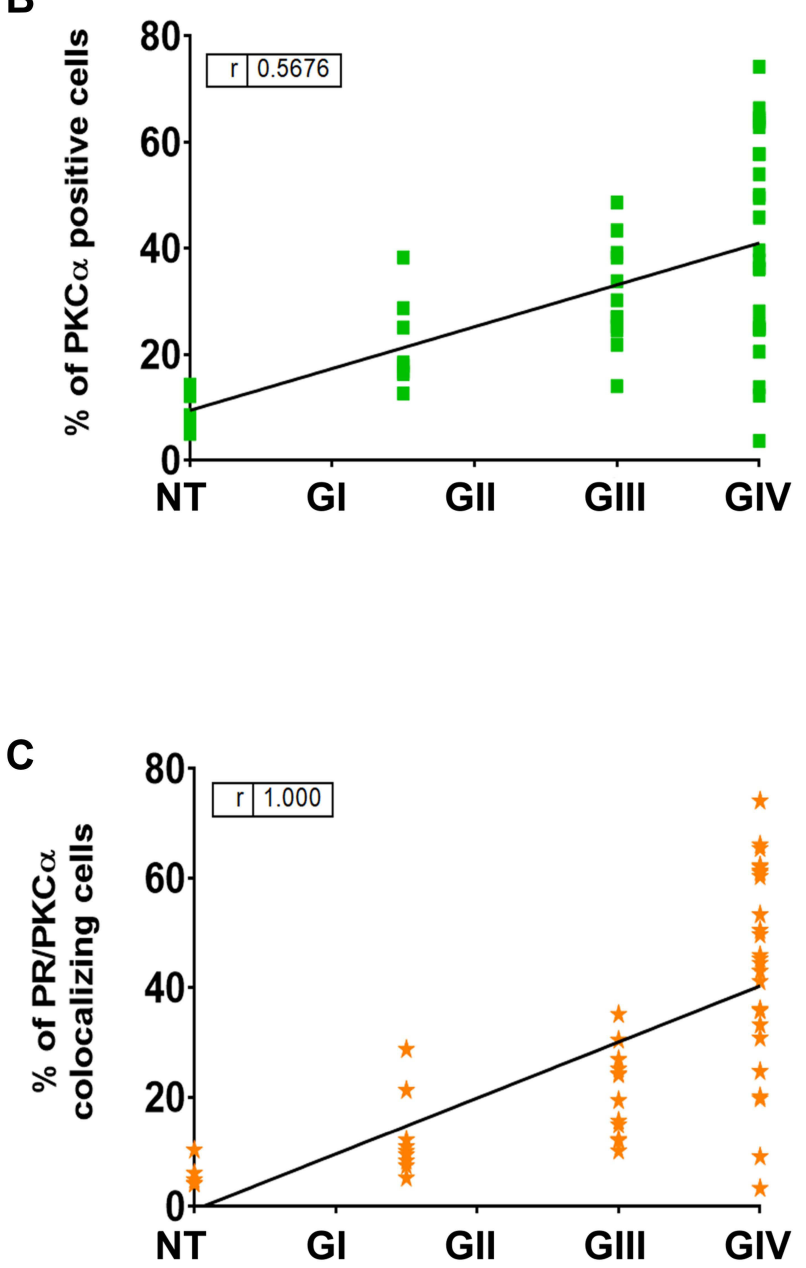

Figure 3 Spearman correlation between tumor grade and \% of positive cells. A Spearman correlation coefficient was calculated to measure the strength of association between tumor grade and \% of positive cells for PR (A), PKC $\alpha$ (B) and their merge (C).

- Low intensity for the interval $[L, f]$,

- Medium intensity for the interval $(f, s]$,

- High intensity for the interval $(s, H]$,
Table 3 Fluorescence Intensity from Each Protein and Their Classification in Intervals

\begin{tabular}{|c|c|c|c|}
\hline Protein & HAG & $\%$ of Samples & FI \\
\hline \multirow[t]{9}{*}{ PR } & \multirow[t]{3}{*}{ I-II } & 66.66 & Low \\
\hline & & 22.22 & Medium \\
\hline & & II.II & High \\
\hline & \multirow[t]{3}{*}{ III } & 25 & Low \\
\hline & & 66.66 & Medium \\
\hline & & 8.33 & High \\
\hline & \multirow[t]{3}{*}{ IV } & 8.0 & Low \\
\hline & & 20.0 & Medium \\
\hline & & 72.0 & High \\
\hline \multirow[t]{9}{*}{ PKC $\alpha$} & \multirow[t]{3}{*}{ I-II } & 70.0 & Low \\
\hline & & 20.0 & Medium \\
\hline & & 10.0 & High \\
\hline & \multirow[t]{3}{*}{ III } & 7.69 & Low \\
\hline & & 61.54 & Medium \\
\hline & & 30.77 & High \\
\hline & \multirow[t]{3}{*}{ IV } & 8.0 & Low \\
\hline & & 28.0 & Medium \\
\hline & & 64.0 & High \\
\hline
\end{tabular}

Note:Bold values indicate the highest percentage of samples ubicated in certain fluorescence values.

Abbreviations: HAG, histological astrocytoma grade; FI, fluorescence intensity. Bold values indicate the highest percentage of samples ubicated in certain fluorescence values.

where $f=L+I$ and $s=f+I$. Each sample was categorized in one of these intervals.

\section{PGR and PRKCA Genes Evaluation}

For the determination of $P G R$ and PRKCA mRNA we used the platform of the California University, Santa Cruz: UCSC Xena (XenaBrowser.net) and the database from TCGA and GTEX for tumor tissue and non-tumor tissue, respectively. For the non-tumor tissue a total of 283 samples from brain cortex of GTEX database were used. For the tumor tissue, we used the TCGA database and obtained 258 samples for grade II (GII), 271 for grade III (GIII) and 166 for grade IV (GIV or GBM). The levels of mRNA were obtained and plotted on Graph Pad Prism 5.0. For this analysis, we used EGFR (Supplementary Figure 4) as positive control expression for GBM. The data are summarized in Table 2.

\section{Spearman Correlations}

To obtain the correlation between the degree of expression of $P G R$ and PRKCA, the gene expression database called 
"TCGA Glioblastoma (GBM)" were used, the samples that did not have data for both genes were eliminated; 172 samples were used and the Spearman coefficient was determined using the GraphPad Prism 8.0.2 program.

\section{Survival Curves}

To evaluate the relationship between gene expression of $P G R$ and $P R K C A$ with patients survival, Kaplan-Meier type curves were performed using the XenaBrowser.net platform, the database "TCGA low grade astrocytoma and glioblastoma," we obtained the following data: for PGR: grade II: 257 samples, grade III: 270 samples, grade IV: 172 samples, for $P R K C A$ : Grade II: 270 samples, Grade III: 270 samples, and Grade IV: 172 samples.

\section{Statistical Analysis}

The results were expressed as the mean \pm SD for $\%$ of positive cells and for their overlap. Statistical analysis between groups was performed with an ANOVA followed by a Dunnet's post-test. A value $\mathrm{P}<0.05$ was considered statistically significant as stated in figure legends. All these analyses were performed in Graph Pad Prism 5.0 (Graph Pad Software, San Diego, CA).

\section{Results}

\section{PR, PKC $\alpha$ Localization and Their Merge Increase According to the Tumor Grade}

Immunofluorescence assays were performed to evaluate the presence of PR, PKC $\alpha$, and their colocalization in astrocytoma biopsies (Figure 1). We observed that the number of PR and $\mathrm{PKC} \alpha$ positive cells increased in accordance with the tumor malignancy grade: the percentage for PR positive cells in the non-tumor tissue (NT) was 6.2\%, GI-II 16.1\%, GIII 26.7\% and GIV (GBM) 51.6\% (Figure 2A). For PKC $\alpha$, the data were as follows: NT 9.2\%, GI-II 22.5\%, GIII31.1\% and GIV $41.5 \%$ (Figure 2B), and for colocalization: $5.9 \%$ for NT, 12.6\% for GI-II, 20.8\% for GIII and 43.9\% for GIV (Figure 2C).

To know if a correlation exists between the tumor grade and the $\mathrm{PR} / \mathrm{PKC} \alpha$ detection, we performed a Spearman
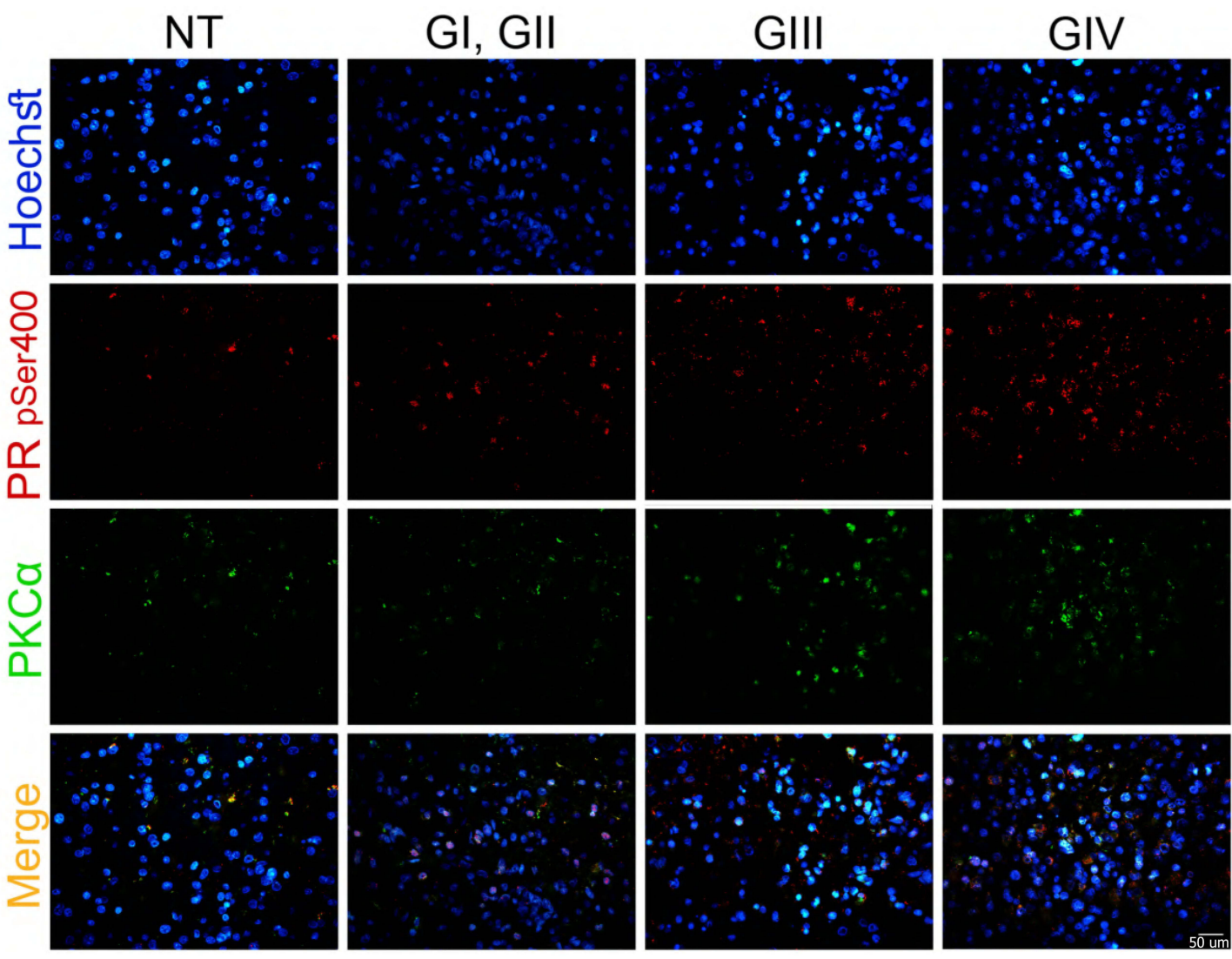

Figure 4 PR pSer400, PKC $\alpha$ detection and their colocalization increased according to the tumor grade. Representative sections of astrocytic tumors from (NT) non-tumor tissue, (G) astrocytomas grade, which were immunostained for PR pSer400 and PKC $\alpha$. Blue: nucleus, green: PKC $\alpha$, red: PR pSer400 and orange: merge between three channels (original magnification, 600x). 
A

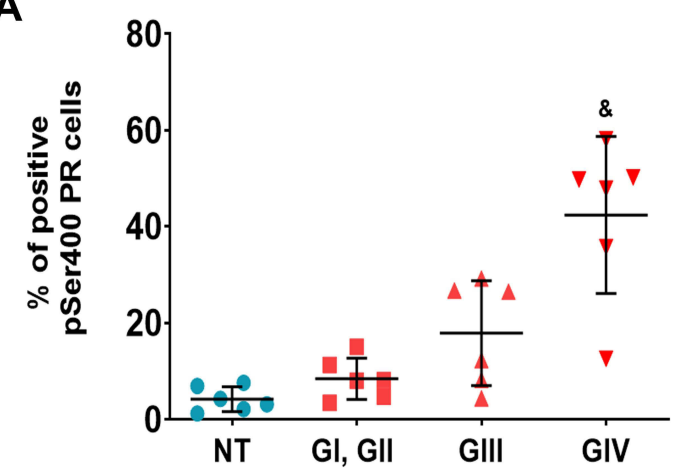

C

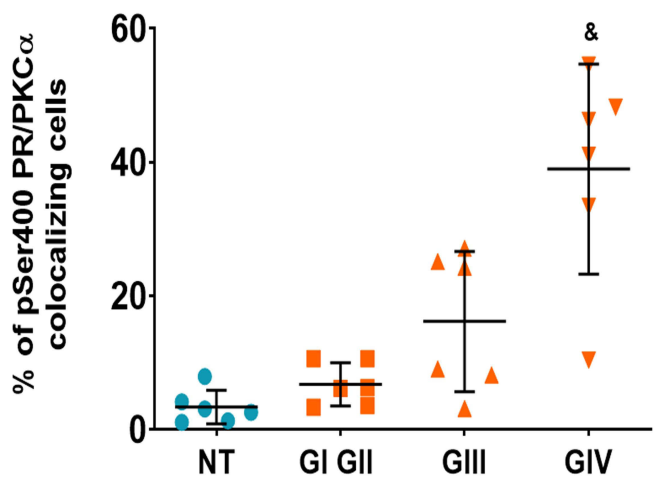

B



D

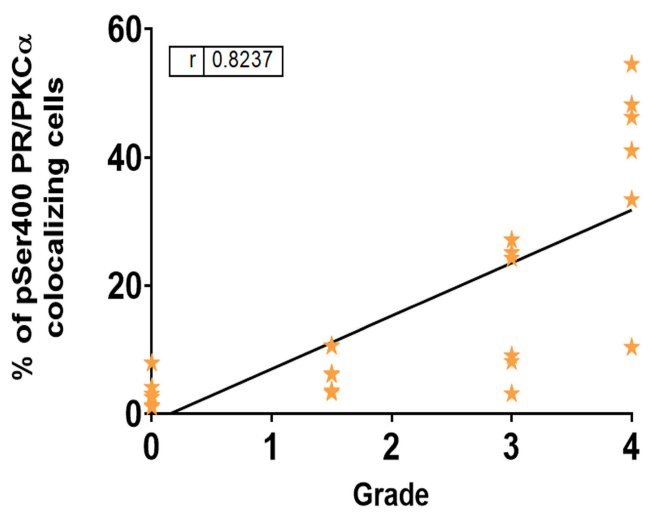

Figure 5 Percentage of positive cells PSer400 PR, PKC $\alpha$ and their merge. Percentage of positive cells for pSer400 PR (A), PKC $\alpha$ (B) and cells overlap PSer400 PR/PKC $\alpha$ (C). For each sample, 25 fields were taken. Results are expressed as the mean \pm SD. Dunnet post-test determined the statistical difference $\left({ }^{\&} p \leq 0.05\right.$ vs all groups). (NT) nontumor, (G) astrocytomas grade. Correlation between the colocalization of pSer400 PR/PKC $\alpha$ and astrocytoma grade (D). Spearman correlation coefficient was calculated to measure the strength of association between PR/PKC $\alpha$ colocalization and tumor malignancy.

Abbreviations: NT, non-tumor tissue; G, astrocytomas grade.

Correlation. We found a positive statistical correlation between PR (Figure 3A), PKC $\alpha$ (Figure 3B), and their colocalization with tumor malignancy grade (Figure $3 \mathrm{C}$ ).

To determine if some features as sex or age could influence PR and PKC $\alpha$ detection, the samples were separated according to the sex in two groups $(\mathrm{F}$ : feminine and M: masculine), but no significant differences were found between sexes (Supplementary Figures 1a-c). No correlation was observed between astrocytomas grades and the age of patients according to detection of $\mathrm{PR}, \mathrm{PKC} \alpha$ and $\mathrm{PR} / \mathrm{PKC} \alpha$ colocalization (Supplementary Figures 2a-c).

\section{Fluorescence Intensity from Each Protein in Immunofluorescence Assays}

We sorted the fluorescence intensity for each protein in three intervals (low, medium, and high) according to the formula described in the Materials and Methods section, ${ }^{28}$ then the samples were classified in accordance with their intensity (Table 3): $66.6 \%$ of the samples from grade I-II showed a low intensity for $\mathrm{PR}$, and $70 \%$ for $\mathrm{PKC} \alpha$, in the case of astrocytomas grade III, $66.66 \%$ for PR and $61.54 \%$ for PKC $\alpha$ of the samples showed a medium intensity, and for grade IV or GBM $72 \%$ for PR and $64 \%$ for $\mathrm{PKC} \alpha$ presented high intensity.

\section{PR pSer400 and PKC $\alpha$ Detection, and Their Colocalization Increased According to the Tumor Grade}

For the analysis of phosphorylation, we randomly took six samples for each group. We found that the percentage of positive cells for pSer400 and their merge with $\mathrm{PKC} \alpha$ increased according to the tumor grade (Figure 4). The mean of cells positive to PR pSer400 in the NT tissue was $4.2 \%, 8.4 \%$ for GI-II, $17.9 \%$ for GIII, and $42.4 \%$ for GIV (Figure 5A), for PKCa this mean was $4.1 \%$ for NT, $8.0 \%$ for GI-II, $20.63 \%$ for GIII and $41.3 \%$ for GIV (Figure 5B). 

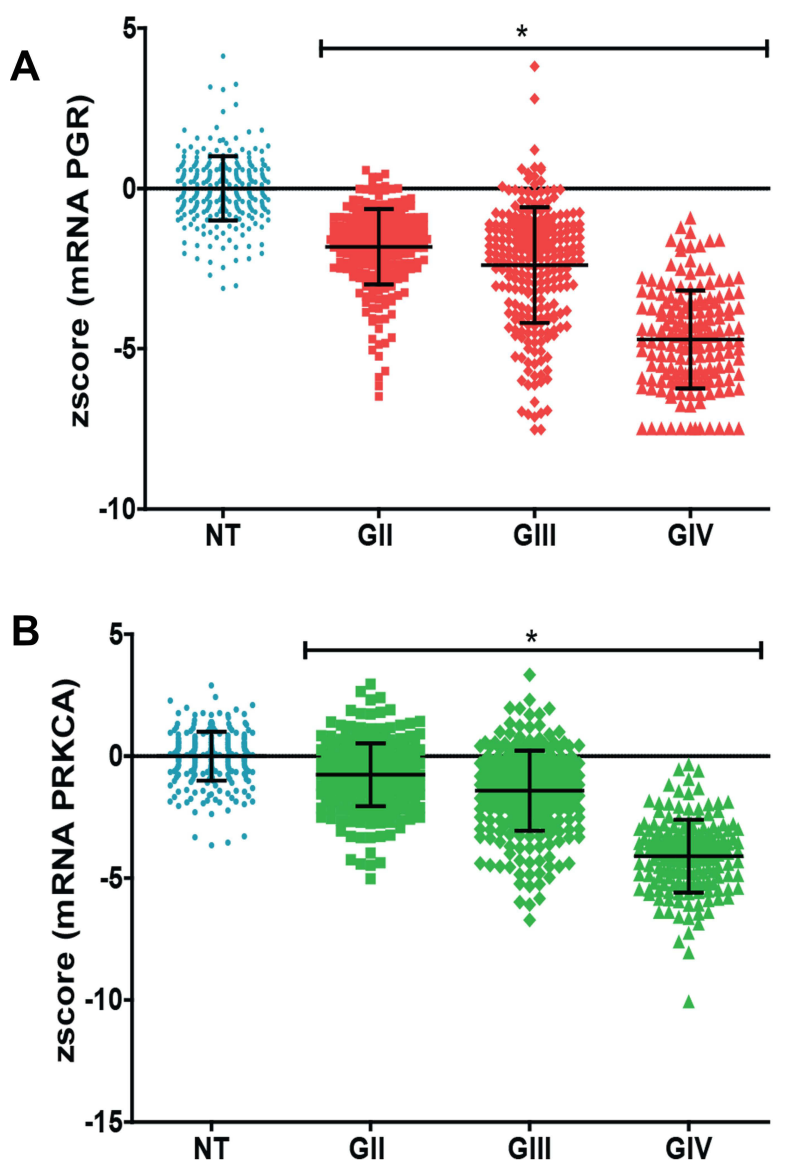

C



Figure 6 Expression of mRNA for PGR and PKCA and its correlation. PGR (A) and PRKCA (B) mRNA expression in normal tissue (NT) and in astrocytomas with different malignancy grade $(G)$. Results are expressed as the mean \pm SD. Dunnet post-test determined the statistical difference $(* P \leq 0.005$ vs $N T)$. Correlation between the expressions of both genes $(\mathbf{C})$. Spearman correlation coefficient was calculated to measure the strength of association between PR and PKC $\alpha$.

The colocalization of these two proteins provided a mean of positive cells of $3.3 \%$ for NT, $6.7 \%$ for GI-II, $16.1 \%$ for GIII, and 38.9\% for GIV (Figure 5C). We performed a Spearman correlation between colocalization of PR pSer400/PKC $\alpha$ with tumor grade, a positive statistical correlation was found (Figure 5D). In Supplementary Figure 3, representative images of PR pSer400 and $\mathrm{PKC} \alpha$ colocalization for each patient are shown. These results suggest an astrocytoma grade-dependent correlation with the detection of PKC- $\alpha$ and PR pSer400.

\section{Expression of $m R N A$ for $P G R$ andPRKCA}

In silico analysis using TCGA data showed that mRNA levels for both genes are proportionally inverse to the tumor grade (Figure 6A and $\mathrm{B}$ ). We observed that no correlation exists at mRNA level between $P G R$ and PRKCA expression (Figure 6C), suggesting that the expression of one of these factors does not depend on the other. For this analysis, we used the gene EGFR (Supplementary Figure 4) as a positive control because many reports indicate that the mRNA level of this gene correlates positively with tumor astrocytoma grade. ${ }^{30}$ From the in silico data, we separated the data according to the patient's sex to determine if a difference exists between mRNA for $P G R$ and PRKCA. No difference was observed between sexes or tumor grade (Supplementary Figures $5 \mathrm{a}$ and $5 \mathrm{~b}$ ).

\section{Expression of PGR and PRKCA Correlation with Patient Survival}

In order to evaluate the relationship between $P G R$ and PRKCA expression (mRNA) with patient survival, Kaplan-Meier graphs using TCGA data were done (Figure 7). Interestingly, patients with astrocytoma grade III and IV with less expression of both factors have a large survival than those with high expression (Figure 6C-F). 

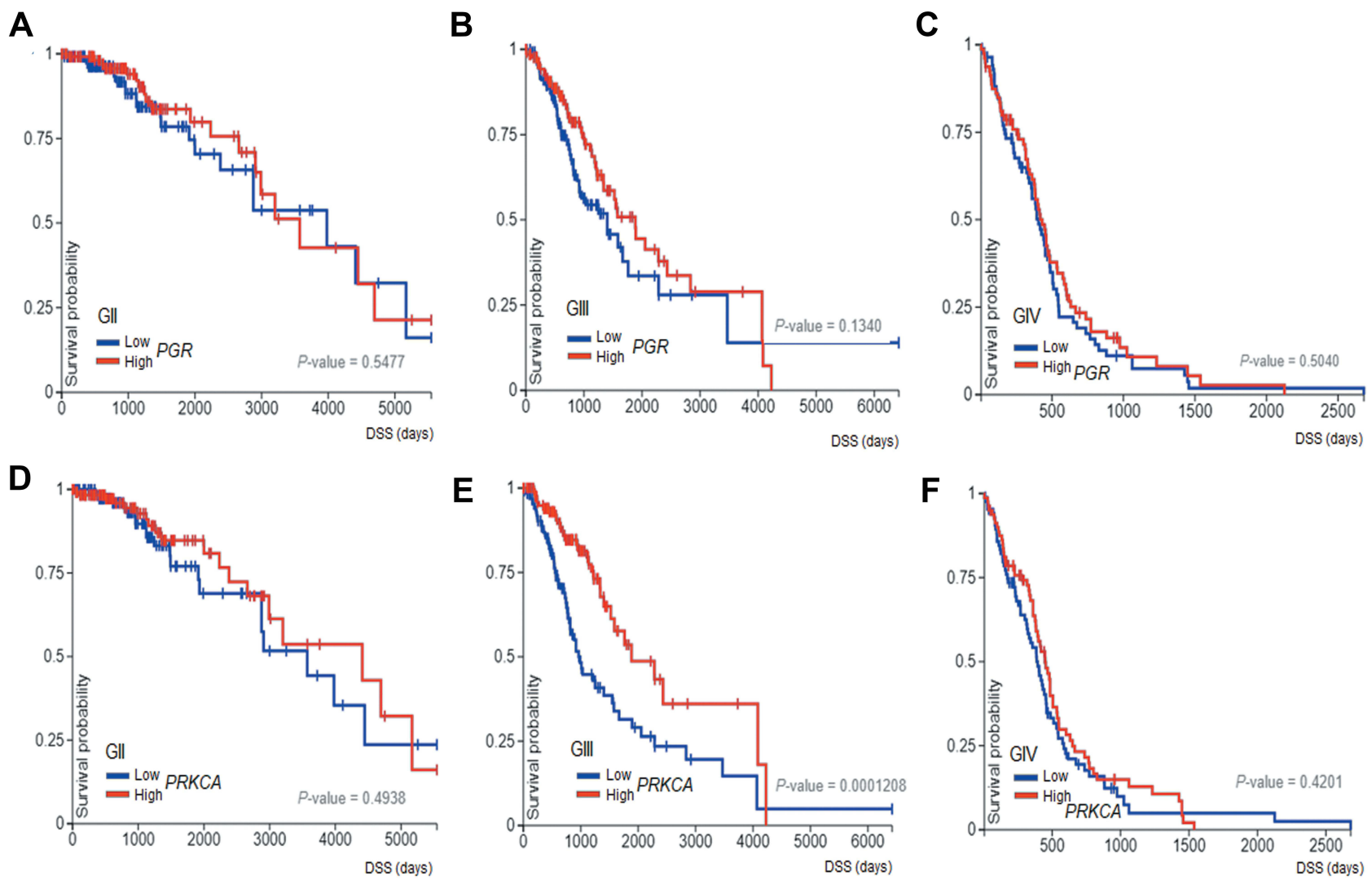

Figure 7 Survival curves. The Kaplan-Meier graphs show survival curves in patients that express PGR and PRKCA in different grades of astrocytomas: Grade II (A and B) Grade III (C and D) and Grade IV (E and F).

Patients with astrocytoma grade II survival are independent of the expression of these factors (Figure 6A and B). The results suggest that the expression level of both factors in high-grade astrocytomas correlates with a poor prognosis.

\section{Discussion}

In this work, we detected the presence of PR, PKC $\alpha$, and the colocalization of both proteins in 46 biopsies from Mexican patients with a diagnosis of astrocytomas grades I-IV. Interestingly, we observed that the number of positive cells for total PR and its phosphorylation at the Ser400 site, as well as PKC $\alpha$ and their respective colocalization, positively correlates with the tumor grade. Previously, a positive relationship between the percentage of PR positive cells with respect to tumor grade had been observed in patient biopsies; however, it had not been compared with respect to non-tumor tissue., ${ }^{9,31}$

The activity of transcription factors is regulated by post-translational modifications such as phosphorylation; PR can be activated by phosphorylation at Ser 400 by
PKC $\alpha$ in human GBM cell lines. ${ }^{28}$ In human glioblastoma cell lines, PKC $\alpha$ can be activated by lysophosphatidic acid receptor $1\left(\mathrm{LPA}_{1}\right)$ which activates $\mathrm{G} \alpha \mathrm{q}$, which in turn activates $\mathrm{PKC} \alpha,{ }^{24}$ the activation of this kinase causes an increase in the transcriptional activity of $\mathrm{PR}^{23}$ that regulates expression of genes involved in proliferation, migration, and invasiveness. ${ }^{32,33}$ In this work, we detected that PR phosphorylated at Ser400 and their colocalization with $\mathrm{PKC} \alpha$ increased according to the tumor grade, which suggests that the PKC $\alpha$ induces PR phosphorylation, which afterward could induce receptor transcriptional activity. ${ }^{23,28,34}$ Phosphorylation sites have been proposed as possible tumor biomarkers; the phosphorylation at Ser294 of PR in breast cancer is associated with bad prognostic. This phosphorylation induces stem cell phenotype and increases signaling pathways activated by growth factors; in relation to this, a use of therapies with antiestrogen activity has been suggested to avoid the recurrence of patients with a high content of pSer294 PR. ${ }^{35}$

Interestingly, we observed that the expression of $P G R$ and $P R K C A$ genes decreased in relation to the malignancy grade of 
astrocytomas, opposite effect observed at the protein level. The abundance of mRNA and the protein levels are unrelated in many cases $^{36}$; in lung adenocarcinoma, 29 genes with at least two isoforms, show a different correlation coefficient mRNA/protein, for example, for OP18 (oncoprotein 18), three of the four isoforms showed a statistically significant correlation between the mRNA abundance and the protein, the fourth isoform showed no correlation between protein and mRNA expression. ${ }^{37}$ On patients with lung adenocarcinoma, some mechanisms that can modify the transcription at mRNA levels have been suggested; the Kozak sequences alterations, the codons polarization, the nonsense lectures, or even these alterations can be attributed to the quantification methods, such as temperature and lifetime of mRNA.$^{36}$ Differences between the transcriptome and proteome studies from samples of the same patient with GBM have been found; in genes as synapsin 1 (SYN1, related to cellular communication), mRNA levels are under-expressed, meanwhile protein is overexpressed. $^{38}$ In another study, a profile of proteins was performed in eight patients with GBM and compared to their respective non-tumor tissue; afterward, they analyzed the relation between $\mathrm{mRNA} /$ protein, they observed that only $2 \%$ of total proteins correlated with their respective mRNA. ${ }^{39}$

Gene mutations could be related with differences between mRNA and protein levels. In chordoid gliomas $P R K C A^{D 463 H}$ transcript is overexpressed compared to $P R K C A^{W T}$ mRNA transcripts. ${ }^{40}$ We determined the presence of punctual mutations in the PGR and PRKCA genes in glioblastoma tissue using the TCGA data bank in the Xena browser platform (Supplementary Figure 6), we found the presence of mutations that provides changes in protein amino acids at the sites: 709, 813 and 836 for PR and 506 for PKC $\alpha$, it would be necessary to study if these transcripts are abundant in GBM compares to NT tissue. Interestingly, Kaplan-Meier curves point out that the expression of mRNA of $P G R$ and PRKCA in different astrocytoma grades correlates with patient survival, indicating the relevance of these factors for this pathology.

\section{Conclusion}

Our results indicate that $\mathrm{PR}$ and its phosphorylation at Ser400 site, as well as PKC $\alpha$ and their colocalization, could be considered as possible malignancy biomarkers for astrocytomas grades I-IV and that the analysis of mRNA expression in GBM is not enough to determine the role of a gene in tumor malignancy.

\section{Ethical Statement}

The pathology slides were obtained from the National Institute of Neurology and Neurosurgery Manuel Velasco Suárez in accordance with the protocol N ${ }^{\circ}$ 67/12 approved by the Institutional Review Board. All patients signed the informed consent and the guidelines outlined in the Declaration of Helsinki were followed.

\section{Acknowledgments}

We thank Carlos Humberto Martínez Álvarez (Universidad Autónoma del Estado de México), MSc. Ángel Jonathan Ruiz Moreno (Facultad de Medicina, Universidad Nacional Autónoma de México) and MSc. Gabriela Piña-Medina (Facultad de Química, Universidad Nacional Autónoma de México) for their technical support.

\section{Funding}

This work was supported by Programa de Apoyo a Proyectos de Investigación e Innovación Tecnológica (PAPIIT) IA201120 and IN219719. Denisse ArcosMontoya is a $\mathrm{PhD}$ student from Programa de Maestría y Doctorado en Ciencias Bioquímicas, Universidad Nacional Autónoma de México (UNAM) and received fellowship 894557 from CONACyT.

\section{Disclosure}

The authors reported no conflicts of interest for this work and declare that they have not known competing financial interests or personal relationships that could have appeared to influence this work.

\section{References}

1. Ostrom QT, Gittleman H, Truitt G, Boscia A, Kruchko C, BarnholtzSloan JS. CBTRUS statistical report: primary brain and other central nervous system tumors diagnosed in the United States in 2011-2015. Neuro Oncol. 2018;20(suppl_4):iv1-iv86. doi:10.1093/neuonc/noy131

2. Ohgaki H. Genetic pathways to glioblastomas. Neuropathology. 2005;25(1):1-7. doi:10.1111/j.1440-1789.2004.00600.x

3. Louis DN, Perry A, Reifenberger G, et al. The 2016 World Health Organization Classification of Tumors of the Central Nervous System; a summary. Acta Neuropatho. 2016;131(6):803-820. doi:10.1007/ s00401-016-1545-1.

4. Furnari FB, Fenton T, Bachoo RM, et al. Malignant astrocytic glioma: genetics, biology, and paths to treatment. Genes Dev. 2007;21 (21):2683-2710. doi:10.1101/gad.1596707

5. Magaña-Maldonado R, Chávez-Cortez EG, Olascoaga-Arellano NK, et al. Immunological Evasion in Glioblastoma. Biomed Res Int. 2016;2016:7487313. doi:10.1155/2016/7487313

6. Wegman-Ostrosky T, Reynoso-Noverón N, Mejía-Pérez SI, et al. Clinical prognostic factors in adults with astrocytoma: historic cohort. Clin Neurol Neurosurg. 2016;146:116-122. doi:10.1016/j. clineuro.2016.05.002 
7. Soubannier V, Stifani S. NF- $\mathrm{kB}$ signalling in glioblastoma. Biomedicines. 2017.

8. González-Agüero G, Gutiérrez AA, González-Espinosa D, et al. Progesterone effects on cell growth of U373 and D54 human astrocytoma cell lines. Endocrine. 2007;32(2):129-135. doi:10.1007/ s12020-007-9023-0

9. Khalid H, Shibata S, Kishikawa M, Yasunaga A, Iseki M, Hiura T. Immunohistochemical analysis of progesterone receptor and Ki-67 labeling index in astrocytic tumors. Cancer. 1997;80(11):2133-2140.

10. Piña-Medina AG, Hansberg-Pastor V, González-Arenas A, Cerbón M, Camacho-Arroyo I. Progesterone promotes cell migration, invasion and cofilin activation in human astrocytoma cells. Steroids. 2016;105:19-25. doi:10.1016/j.steroids.2015.11.008

11. Germán-Castelán L, Manjarrez-Marmolejo J, González-Arenas A, González-Morán MG, Camacho-Arroyo I. Progesterone induces the growth and infiltration of human astrocytoma cells implanted in the cerebral cortex of the rat. Biomed Res Int. 2014;2014:1-8. doi:10.1155/2014/393174

12. Llaguno-Munive M, Medina LA, Jurado R, Romero-Piña M, GarciaLopez P. Mifepristone improves chemo-radiation response in glioblastoma xenografts. Cancer Cell Int. 2013;13(1):29. doi:10.1186/ 1475-2867-13-29

13. Llaguno-Munive M, Romero-Piña M, Serrano-Bello J, Medina LA, Uribe-Uribe N, Ana Salazar AM. Mifepristone overcomes tumor resistance to temozolomide associated with DNA damage repair and apoptosis in an orthotopic model of glioblastoma. Cancers (Basel). 2018;11(16):1-15. doi:10.3390/cancers11010016

14. Escriva H, Bertrand S, Laudet V. The evolution of the nuclear receptor superfamily. Essays Biochem. 2004;40:11-26. doi:10.1042/ bse 0400011

15. McEwan IJ. Nuclear receptors: one big family. MethodsMol Biol 2009;505:3-18.

16. Hagan CR, Daniel AR, Dressing GE, Lange CA. Role of phosphorylation in progesterone receptor signaling and specificity. Mol Cell Endocrinol. 2012;357(1-2):43-49. doi:10.1016/j.mce.2011.09.017

17. Qiu M, Lange CA. MAP kinases couple multiple functions of human progesterone receptors: degradation, transcriptional synergy, and nuclear association. J Steroid Biochem Mol Biol. 2003;85(2-5):147-157. doi:10.1016/S0960-0760(03)00221-8

18. Zhang Y, Beck CA, Poletti A, Edwards DP, Weigel NL. Identification of phosphorylation sites unique to the $\mathrm{B}$ form of human progesterone receptor. In vitro phosphorylation by casein kinase II. $J$ Biol Chem. 1994;269(49):31034-31040. doi:10.1016/S0021-9258(18)47386-3

19. Zhang Y, Beck CA, Poletti A, et al. Phosphorylation of human progesterone receptor by cyclin-dependent kinase 2 on three sites that are authentic basal phosphorylation sites in Vivo. Mol Endocrinol. 1997;11(6):823-32. doi:10.1210/mend.11.6.0006

20. Knotts TA, Orkiszewski RS, Cook RG, Edwards DP, Weigel NL. Identification of a phosphorylation site in the hinge region of the human progesterone receptor and additional amino-terminal phosphorylation sites. $J$ Biol Chem. 2001;276(11):8475-8483. doi:10.1074/jbc.M009805200

21. Lange CA, Shen T, Horwitz KB. Phosphorylation of human progesterone receptors at serine-294 by mitogen-activated protein kinase signals their degradation by the $26 \mathrm{~S}$ proteasome. Proc Natl Acad Sci U S A. 2000;97(3):1032-7. doi:10.1073/pnas.97.3.1032

22. Pierson-Mullany LK, Lange CA. Phosphorylation of progesterone receptor serine 400 mediates ligand-independent transcriptional activity in response to activation of cyclin-dependent protein kinase 2 . Mol Cell Biol. 2004;24(24):10542-10557. doi:10.1128/ MCB.24.24.10542-10557.2004

23. Marquina-Sánchez B, González-Jorge J, Hansberg-Pastor V, et al. The interplay between intracellular progesterone receptor and $\mathrm{PKC}$ plays a key role in migration and invasion of human glioblastoma cells. J Steroid Biochem Mol Biol. 2017;172:198-206. doi:10.1016/j. jsbmb.2016.10.001
24. Valdés-Rives SA, de la Fuente-granada M, Velasco-Velázquez MA, González-Flores O, González-Arenas A. LPA 1 receptor activation induces $\mathrm{PKC} \alpha$ nuclear translocation in glioblastoma cells. Int $J$ Biochem Cell Biol. 2019;110:91-102. doi:10.1016/j. biocel.2019.03.003

25. Steinberg SF. Structural basis of protein kinase $\mathrm{C}$ isoform function. Physiol Rev. 2008;88(4):1341-1378. doi:10.1152/ physrev.00034.2007

26. Cameron AJ, Procyk KJ, Leitges M, Parker PJ. PKC alpha protein but not kinase activity is critical for glioma cell proliferation and survival. Int J Cancer. 2008;123(4):769-779. doi:10.1002/ijc.23560

27. Mandil R, E Ashkenazi, M Blass, et al. Protein kinase $\mathrm{C} \alpha$ and protein kinase C $\delta$ play opposite roles in the proliferation and apoptosis of glioma cells. Cancer Res. 2001;61(11):4612-4619.

28. González-Arenas A, Peña-Ortiz MÁ, Hansberg-Pastor V, et al. Pkc $\alpha$ and $\mathrm{pkc} \delta$ activation regulates transcriptional activity and degradation of progesterone receptor in human astrocytoma cells. Endocrinology. 2015;156(3):1010-1022. doi:10.1210/en.2014-1137

29. Villegas-Pineda JC, Garibay-Cerdenares OL, Hernández-Ramírez VI, et al. Integrins and haptoglobin: molecules overexpressed in ovarian cancer. Pathol Res Pract. 2015;211(12):973-981. doi:10.1016/j. prp.2015.10.002

30. Puliyappadamba VT, Hatanpaa KJ, Chakraborty S, Habib AA. The role of NF-KB in the pathogenesis of glioma. Mol Cell Oncol. 2014;1 (3):e963478. doi:10.4161/23723548.2014.963478

31. González-Agüero G, Ondarza R, Gamboa-Domínguez A, Cerbón MA, Camacho-Arroyo I. Progesterone receptor isoforms expression pattern in human astrocytomas. Brain Res Bull. 2001;56 (1):43-48. doi:10.1016/S0361-9230(01)00590-1

32. González-Arenas A, Valadez-Cosmes P, Jiménez-Arellano C, LópezSánchez M, Camacho-Arroyo I. Progesterone-induced blocking factor is hormonally regulated in human astrocytoma cells, and increases their growth through the IL-4R/JAK1/STAT6 pathway. $J$ Steroid Biochem Mol Biol. 2014;144(PB):463-470. doi:10.1016/j. jsbmb.2014.09.007

33. Hernández-Hernández OT, Camacho-Arroyo I. Regulation of gene expression by progesterone in cancer cells: effects on cyclin D1, EGFR and VEGF. Mini Rev Med Chem. 2013;13(5):635-42. doi:10.2174/1389557511313050002

34. Hernández-Hernández OT, González-García TK, Camacho-Arroyo I. Progesterone receptor and SRC-1 participate in the regulation of VEGF, EGFR and Cyclin D1 expression in human astrocytoma cell lines. J Steroid Biochem Mol Biol. 2012;132(1-2):127-134. doi:10.1016/j.jsbmb.2012.04.005

35. Knutson TP, Truong TH, Ma S, et al. Posttranslationally modified progesterone receptors direct ligand-specific expression of breast cancer stem cell-associated gene programs. J Hematol Oncol. 2017;10(1). doi:10.1186/s13045-017-0462-7.

36. Maier T, Güell M, Serrano L. Correlation of mRNA and protein in complex biological samples. FEBS Lett. 2009;583(24):3966-3973. doi:10.1016/j.febslet.2009.10.036

37. Chen G, Gharib TG, Huang C-C, et al. Discordant protein and mRNA expression in lung adenocarcinomas. Mol Cell Proteomics. 2002;1(4):304-313. doi:10.1074/mcp.M200008-MCP200

38. Lemée J-M, Clavreul A, Aubry M, et al. Integration of transcriptome and proteome profiles in glioblastoma: looking for the missing link. BMC Mol Biol. 2018;19(1):13. doi:10.1186/s12867-018-0115-6

39. Song YC, Lu G-X, Zhang H-W, et al. Proteogenomic characterization and integrative analysis of glioblastoma multiforme. Oncotarget. 2017;8(57):97304-97312. doi:10.18632/oncotarget.21937

40. Rosenberg S, Simeonova I, Bielle F, et al. A recurrent point mutation in PRKCA is a hallmark of chordoid gliomas. Nat Commun. 2018;9 (1). doi:10.1038/s41467-018-04622-w 


\section{Publish your work in this journal}

OncoTargets and Therapy is an international, peer-reviewed, open access journal focusing on the pathological basis of all cancers, potential targets for therapy and treatment protocols employed to improve the management of cancer patients. The journal also focuses on the impact of management programs and new therapeutic agents and protocols on patient perspectives such as quality of life, adherence and satisfaction. The manuscript management system is completely online and includes a very quick and fair peer-review system, which is all easy to use. Visit http://www.dovepress.com/ testimonials.php to read real quotes from published authors. 